\title{
The Economic Effects of a Marathon as a Sport Tourism Event
}

\author{
By Gregory T. Papanikos*
}

\begin{abstract}
Marathons are sport tourism events taking place in many cities around the globe. Economic impacts studies have shown that there exist positive economic effects for the host city but the economics literature has questioned the applied methodology. Costbenefit analyses and general equilibrium approaches have shown that the economic effects may not be positive. This study reviews this literature using an eclectic approach. It emphasizes the long term impacts of promoting exports and attracting foreign direct investment. The Athens marathon is used as a case study.
\end{abstract}

Keywords: Athens, Economic impact, Marathon.

\section{Introduction}

This paper provides a brief overview of the literature of the economic effects of sport tourism events with emphasis on marathons. In the last decades, such events have been used as promotion vehicles to attract more visitors. The economic analysis of their effects has been controversial. Many economists question the economic impact methodology is biasing the results in favor of hosting the events. Other techniques which are consistent with the appropriate application of economic methods and analysis show that the economic effects might turn out to be negative. They therefore argue that these events are a waste of taxpayers' money. They organized for the benefit of a small minority of vested interests with political power to influence the local authorities and the mass media.

It is argued that economic impacts studies have not only been applied incorrectly to measure the economic effects of sport tourism events but it was done so on purpose. However, further arguments are made that the economic analysis of these events is inadequate because most of the studies, with very few exceptions, look only at short-term economic effects, economic impact studies included. The long-term economic effects are ignored even if they might be substantial. In particular, the publicity that such events create at a national and international level sends a signal to the world that this locality, city or country is open for business. This will increase exports and bring in more non-local investment.

Studies which have analyzed the marketing of sport tourism events and have suggested policies to increase the positive economic effects ignore this long-term effect. I do not know any published academic study which has

\footnotetext{
* President, ATINER, Greece and Honorary Professor of Economics, University of Stirling UK.
} 
demonstrated how the organization of sport tourism events has been used to increase exports and induce an inflow of foreign investment ${ }^{1}$. There are many studies that deal with event related investments but not with investments which result from the event's publicity and is unrelated to the running of the actual event. These long-term impacts may explain why so many countries and cities are biding to organize such sport tourism events even though a valid economic impact study may indicate negative economic effects.

This paper discusses the issues of short-term and long-term impacts of sport tourism events with emphasis on marathons. A special reference is made to Athens. The discussion is organized in five sections including this introduction. The next section presents selected studies which measure the economic effects of sport tourism events. This literature has grown along side with the massive increase in small, medium and mega sport tourism events. For almost every such event there is an economic impact study either ex ante and/or ex post. These studies are not reviewed here. Instead a subjective selection is made of those studies which provide critical examples and reviews of the applied methodology. Subsequently, the paper discusses the economic effects of marathons. Last, the paper provides some thoughts on the Athens sport tourism events including its annual marathon, and concludes.

\section{Selected Literature Review}

Marathon events are sport tourism events. In the last few decades, these events have been used by many destinations to boost their tourism demand. Getz (2008) reviews the concept of event tourism both as a profession and as an academic discipline. The number of participants either as athletes or attendants determine and the size of the event: small, medium and mega events. The Olympic games and the Football World Cup belong in the latter category. The size of an event determines the extent of its publicity: local publicity (Athens), national publicity (Greece), international publicity (European) and global publicity. Publicity is important not only of its potential short-term and long-term benefits but for the stakeholders who undertake the organization, management and marketing of such events. Politicians such as city councilors look at publicity as an indication of success of sport tourism events.

This literature is dominated by managerial and marketing concerns rather than economic impact issues. Most of the literature takes for granted that the overall economic impacts are positive and every community should welcome these events. In most cases the measurement of the economic effect of such events is short-term and usually is the result of economic impact studies based

\footnotetext{
${ }^{1}$ This is not true though for those government authorities which undertake the organization of such events especially mega events like the Olympic games. In 1999, I visited Sydney as a member of a Greek official mission to be informed on Sydney's preparation for the 2000 Olympic games in order to learn from their experiences and be used for the 2004 Athens games. The government of New South Wales made all the preparations to take full advantage of the long-term economic effects from hosting the games which primarily included exports and capital inflows.
} 
on multipliers. Kurtzman (2005), among many others, provides an overview of the economic impact of sport tourism studies. An early discussion of this literature is provided by Burgan and Mules (1992). Recent examples of economic impact studies include the economic impact of the Beijing Olympic Games in 2008 (Li et al. 2013), Huang et al. (2014) for three sports events in China including the Shanghai International Marathon, and many others as we shall see below.

Economic impact studies are extensively used as an information tool to decide on whether an event should be hosted by a local entity (province, county, city etc) especially if it requires the use of taxpayers' money. Economic impact studies tend to overestimate the net economic benefits for political reasons (Crompton 2006). This is the reason that in the relevant literature economic impact studies have come under the scrutiny of economists who claim that these studies overstate the economic benefits and understate or even worse ignore the costs. The criticism becomes even more cynical because they question their motivation which is not to produce an objective economic impact analysis but to persuade the public even though they now that the economic impact is not positive. They do this because they are being paid as consultants by those who have a vested economic interest to host the event. These include local tourist business, local politicians and sports organization because such events generate wide publicity and increase the politicians chances to be re-elected. Crompton (2006) discusses this issue of how politics affect the overestimation of the economic benefits in economic impact studies. He gives an example of four economic impact studies for the same project which found diametrically different economic effects. Three economic impacts studies projected net benefits and substantial net losses.

Other methods of measuring the economic effect may not support the hosting of a sport tourism event. For example, Taks et al. (2011) used two methods to estimate the effects of the 2005 Pan-American Junior Athletic Championships in the city of Windsor, Canada. The economic impact analysis estimated a positive effect of $\$ 5.6$ million for the city. The alternative method of a cost-benefit analysis came up with a negative economic effect of $\$ 2.4$ million ${ }^{1}$. These are important results because a negative economic effect implies that the event should not be hosted unless the cost is covered by noneconomic benefits enjoyed by local residents such as national pride and cultural affinity with the event ${ }^{2}$.

Matheson (2009) questions the magnitudes of the economic multipliers used in the economic impact studies ${ }^{3}$. He rejects the use of economic multipliers (the use of input-output models which are used to derive them)

\footnotetext{
${ }^{1}$ Furthermore, de Nooij (2014) have re-estimated the economic effect and found that the negative economic impact was three times as large.

${ }^{2}$ Cultural affinity explains why Greeks wanted so much to organize the Olympic games while they have never seriously considered to organize a Football World Cup which is much smaller in size.

${ }^{3}$ Among many studies that show the same skepticism see Baade and Dye (1988), Owen (2005) and Coates (2007).
} 
because they do not take into consideration the dynamics of the economic changes which might result from the organization of the mega event itself. Most economists tend to agree with this. Studies by economists have found either mixed or negative effects from hosting sport tourism events. For example, Szymanski (2002) finds a negative impact on economic growth from hosting a Football World Cup. Similarly, Baade and Matheson (2004) found ex post negative economic effects of the 1994 Football World Cup held in USA instead of the expected positive economic gains. Equally, Porter and Fletcher (2008) provide an ex post evaluation of 1996 Summer Olympic Games and the 2002 Olympic Winter Games. They conclude that the economic effects were insignificant.

Other techniques exist such as computable general equilibrium technique and contingent valuation methods. A discussion of the former is provided by Dwyer et al. (2004). The latter technique was used by Papanikos (2003) to evaluate the post Olympic use of the 2004 venues. Carson (2012) and Hausman (2012) provide an excellent and critical overview of contingent valuation methods which is costly and difficult to implement but provides an accurate estimate of the actual benefits and costs of hosting a sport tourism event.

Other microeconomic approaches have been applied to measure economic effects. Lamla et al. (2014) used actual data from more than 700 Swiss hotels and restaurants during the EURO 2008 soccer championship in Switzerland. The effects were mixed some firms benefited while other experienced a loss. Overall the effect was negative. Actually hotels experienced a decline in sales relevant to the same month (June) of the previous year. This was due to a decrease in the number of congresses and conferences during the month that football games were scheduled. The authors also examined the long term effects of hosting such a sport tourism event.

They found a negligible long term economic effect. Long-term effects have also been previously examined by Spilling (1996) and Jasmand and Maennig (2008). The former study finds modest long-term impact of the 1994 Lillehammer Winter Olympics but as the author claims "out of proportion to the huge costs of hosting the Games". The latter study found positive long-term economic growth effects in the German regions which hosted the 1972 Olympic Games relative to regions that did not host them. However, there was no effect on employment. As we shall see below, Rose and Spiegel (2011) followed a different approach to sport tourism events such as the Olympic Games and Football World Cup. They claim that those countries which organize such events or even bid unsuccessfully to host these games send a signal to the world that are open (liberalized) economies and they are here for business. They found long term positive effect on exports and investment which increase economic growth and create employment. Even though their approach has been criticized on methodological grounds (selection bias), nevertheless there is no doubt that countries which bid to host such events do so because they expect a positive effect on their future economic development.

Baumann et al. (2009) used daily airplane arrival data to measure the effect of three sport tourism events in Hawaii. They found positive impacts. 
The Honolulu Marathon increased net arrivals from 2,183 to 6,519, the Pro Bowl from 5,596 to 6,726 and the Ironman Triathlon from 1,880 and 3,583 net visitors. However, they do not provide economic estimates of the effects.

Summarizing, this literature can be classified into two categories. First, ex ante and ex post studies measure the economic effects of sport tourism events. It seems that those who are directly involved with organizing, managing and marketing such events tend to argue that the economic effects are positive and much higher than the costs. Even if this is not the case, they argue that these events are more than economic business and provide satisfaction to local people who, they assume, are willing to pay the extra cost through taxes. On the other hand, most economists have argued and have shown that these events do not bring more money into the local economy and taxpayers money can be spent more efficiently and effectively in providing other services to the community. Sport tourism events, they argue, is an excuse to distribute income from the many who do not have political power to few who can influence political decisions.

The second strand of the sport tourism event literature deals with the organization, the management and the marketing of the event. They claim that if these are done efficiently and effectively, the economic benefits will be maximized and the costs will be minimized. Thus, it is not the event itself that has a great economic effect but its efficient and effective use. For example, many cities have hosted the Olympic Games, some have benefited (i.e. Barcelona, Sydney) from them but others have not done so well (i.e. Montreal, Athens, Atlanta). An important aspect of this marketing and management literature is the involvement of the visitors with the destination. As it is recognized in the literature of sport tourism, the initial motive of the visitor is the involvement with the sport and not the destination. However, the revisit and the word of mouth effects are related with the tourists' involvement with the destination. This is where marketing plays a role in enhancing this involvement (King et al. 2015, Filo et al. 2013, Green 2001).

Marathons are smaller events but they are organized as annual events in many cities around the world. Athens organizes what it calls the authentic marathon because runners use the ancient classical route from the village of Marathon to the center of Athens. The economic impact of marathons as a sport tourism event is examined in the next section of this paper.

\section{Marathon's Economic Effects}

Marathons are usually organized by cities and the decision making process involves many stakeholders. Figure 1 depicts the decision making process to host marathon sport tourism event in a modern democratic society ${ }^{1}$. This is a typical description of how a decision is made to host a regular marathon sport tourism event usually as an annual event. Ideally, everything starts from local

\footnotetext{
${ }^{1}$ The Athens Marathon was initiated by the Greek Junta in 1972 and it was far from being a democratic decision.
} 
citizens and in some cases it might be the idea of only one person who can mobilize resources and political support. Sooner or later though a critical mass of local citizens must run behind the idea and this has to come through the local government with the support of local business interests and sport associations.

Figure 1. The Decision to Host a Marathon Sport Tourism Event

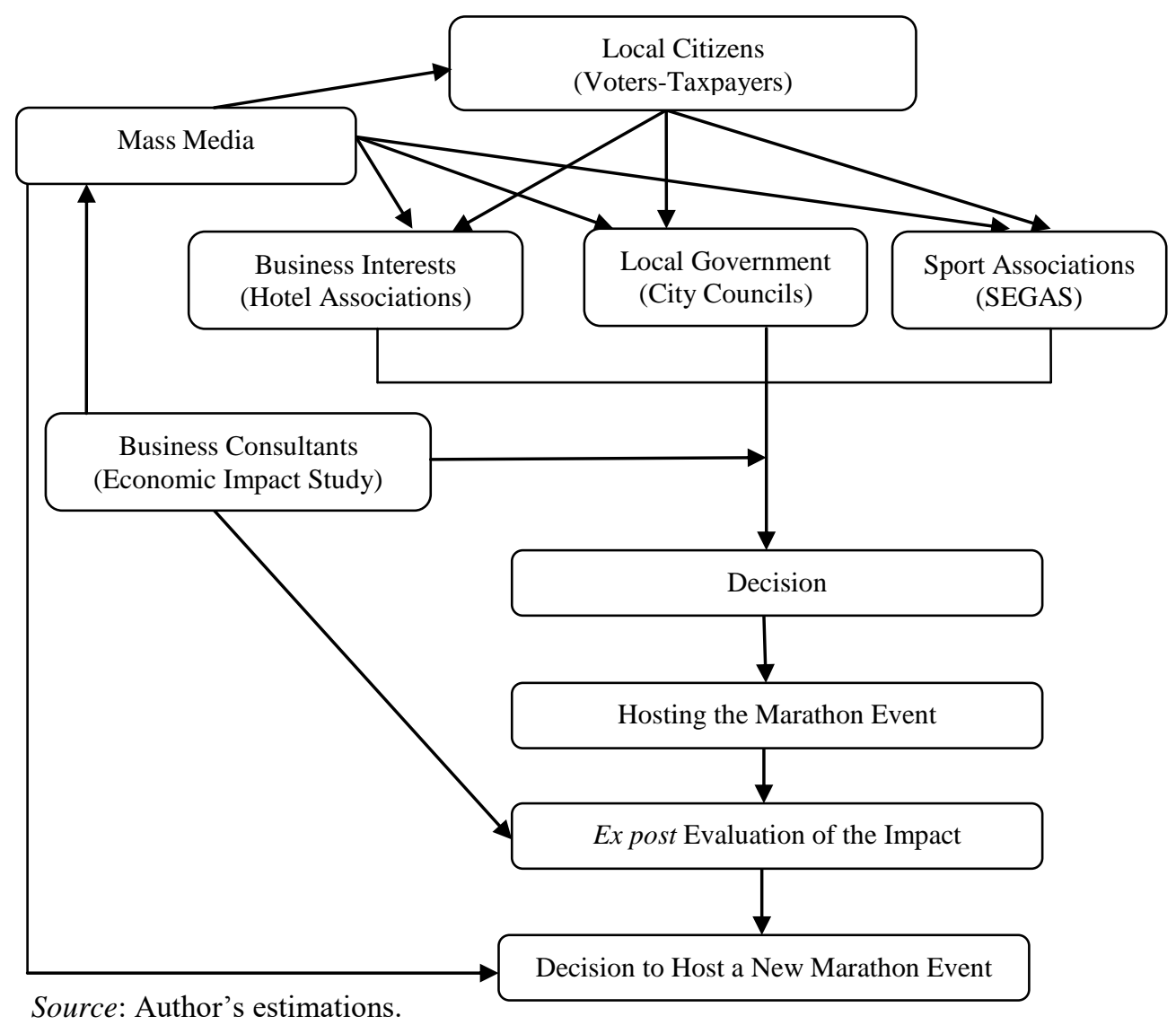

The local media play an important role throughout this process since they reflect the central tendency of the public opinion. Once this idea reaches the decision board of all stakeholders (city council, business and sport associations), there might be the request for a formal economic evaluation of the project. Business consultants and professional economists are called in to produce an economic impact study. At this stage, however, the decision is favorable and most consultants are more than willing to satisfy their customers which are the supporters of the project ${ }^{1}$. The opponents of a sport tourism event

\footnotetext{
${ }^{1}$ As Crompton (2006: 69) put it "Consultants supposedly are hired to provide independent evidence, but in many cases, that evidence is manipulated or selectively presented to tell clients what they want to hear ... A consulting organization that fails to deliver the economic-impact numbers that its client expects is unlikely to receive either repeat business from that client or new commissions from others. The motive of sponsors frequently is to seek proof to support an established position, and clients expect to get what they pay for!"
} 
commission research vary rarely, to prove that the economic impact is negative. Crompton (2006) discusses such a case where four economic impact studies were commissioned for the same project by four different stakeholders. It included a study commissioned by a group of people who opposed the project.

Ideally, if the organization of the first marathon sport event goes well, then a second one will be organized. This decision should be based on the number of participants, particularly non-locals. However, the role of mass media is very critical in shaping public opinion. All marathon events attract media attention and usually are favorable. Ideally again this decision should be based on an ex post economic assessment of the first marathon event.

The most important studies that measure the economic effect of a marathon ${ }^{1}$ sport tourism event belong to the second strand of the literature presented in the previous section. Not only they measure the economic impact as a justification to host the run but at the same time policies are recommended to maximize the economic benefits from organizing the event. And since the organization of a marathon event is usually an annual event which takes place during the same period every year, building fame around the event can have positive long term economic consequences. At least, this is the goal of all those who have a vested interest in events such as local businesses, local politicians and local sport organizers. But this goal is restricted to the event itself and no attempt is made to take advantage of potential long term synergies. In other words, success is measured by increasing the number of participants every year and not with possible side effects that this event might have such as exports and investment.

Most of the marathon studies analyze consumer (expenditure) behavior during the event using survey methods ${ }^{2}$. A number of participants are selected and interviewed using a questionnaire which is filled either during or after the event. The overall economic effect depends on a number of factors which these studies aim at measuring (Gratton et al. 2006, Crompton 1999, Crompton and Lee 2000). These factors include the following.

1. The number of international tourists (participants and attendants). A distinction is made between local and nonlocal as well as national and international arrivals. The reason is that they have different spending propensities.

2. The gender of participants because women tend to spend more.

3. The number of overnight stays per tourist because the total spending per participant depends on the number of stays. Accommodation cost and dining in the restaurant are important elements of consumer

\footnotetext{
${ }^{1}$ The marathon is a running race of mixed distance and not only the classical distance. Also, the word marathon is used for non-running sport tourism event such as the Engadin Ski Marathon (Beritelli et al. 2004).

${ }^{2}$ In tourism studies is common practice the measurement and analysis of visitors' expenditures. An evaluation of these methods and models is given by Frechtling (2006). Also Papanikos (2005) has analyzed spending of international tourist arrivals in Greece.
} 
spending during a marathon event. This affects the propensity to spend on a daily basis.

4. The number of "time-switchers", "casuals", "escapees" and revisitors. In the first group belong all those who would visit the city anyway but plan their arrival to coincide with the marathon event. It might also include visitors who will come to the city anyway but do not want to coincide with the event. Casuals are all those who happened to be in the city for other reasons and decided to follow some of the activities of the event. Finally, "escapees" are local residents who decide to leave the city and go somewhere else to avoid the noise and other displeasures created by large crowds, which includes traffic congestion, noise, low quality service from restaurants and other shops. Marathons are annual events. It is important that this year's visitors are satisfied so much that they come next year bringing more people. Revisiting of a marathon event is part of the measurement of success.

The overall economic effect of a sport tourism event, such as a marathon event, is depicted in Figure 2. The literature, briefly reviewed in the previous section of this paper, analyses only one aspect of this effect. It does not take into account the post event effect on exports and investment inflows. This is explicitly shown in Figure 2 and discussed further below in this section. The top box of Figure 2 is related to the managerial decision to host and organize a marathon event. This is not an easy decision and many authorities (such as city councils), before deciding, ask for an economic impact assessment of the marathon event. These are called ex ante economic impact studies. They are rarely followed though by an ex post economic impact study. The ex ante studies are usually commissioned by those who propose the organization of the event, usually a city council but other stakeholders as well. As mentioned above, this is one of the reasons why many economists are very skeptical. They claim these are attempts to redistribute public money rather than to create new wealth. This is particularly true when the hosting of an event requires the building of an infrastructure with high sunk costs financed by tax payers' money (Gratton et al. 2005). 
Figure 2. The Overall Economic Effect of a Marathon Event

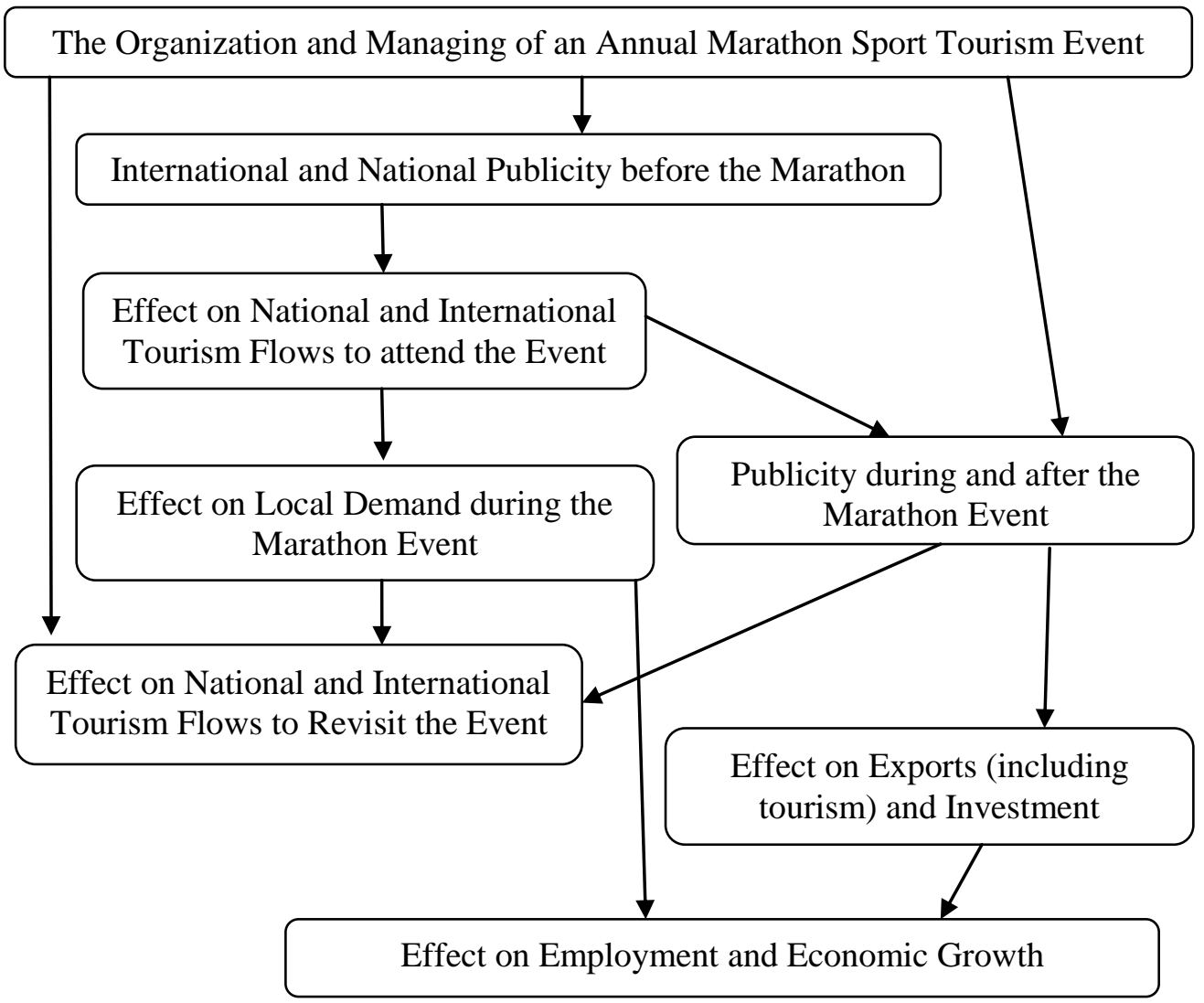

Source: Author's estimations.

A large number of the international and national attendance of marathon event tourists has two effects. First, it has a temporary positive effect on local demand. This includes spending on accommodation, foods and beverages, sport equipment, event merchandize, and general shopping in the city. These are the economic effects that most economic impact studies take into consideration when they evaluate the economic impact of a marathon event. For example, Wicker et al. (2012) estimated the economic impact of three German marathon events (Cologne, Bonn and Hanover) including the intention of the participants and attendants to revisit the city. They found considerable differences in the daily consumer expenditures. In Cologne participants spent a daily average of $€ 90.16$, in Hanover $€ 57.61$ and in Berlin $€ 43.39$. The average stay was 1.6 days. These consumer expenditures are the direct impact. To find the total effect, this spending is multiplied by an estimate of the economic multiplier to calculate the total impact (Brewer and Freeman 2015). This then is the final economic impact which is captured by an impact on local Gross Domestic Product (economic growth) and an increase in local employment.

Second, when a large flow of international and national tourist attend and participate in a marathon event it has an impact on publicity during an after the event. If the experience of the attendants and participants is positive, then there is a high probability to revisit the marathon event and through the word of mouth effect to induce other people to attend. This is only one aspect of the 
publicity during and after the event. The other aspect is the systematic creation of a memorable consumer experience by the marketing efforts of the organizing authorities of the marathon event. Kruger and Saayman (2012) analyzing the "Two Oceans Marathon" in South Africa found four critical factors in securing consumer satisfaction with the amenities (i.e. parking) and marketing being the most important ones. They concluded that the organizing authorities should accommodate the spectators' needs in order to leave the event with a memorable experience.

Davakos (2007) measured the economic impact of the Cooper River Bridge Run on the Lowcountry region of South Carolina, specifically on the city of Charleston and town of Mt. Pleasant. The overall economic impact of the 2004 Marathon was estimated at $\$ 14.3$ creating 336 local jobs. The average stay was 2 nights. Brewer and Freeman (2015) have estimated the average daily spending in Gainesville, Florida to $\$ 80$ dollars for overnight visitors and less than 50 of those who did not use paid accommodation. The average stay was 2 nights.

Cobb and Olberding (2007) analyzed the economic impacts of the 2006 Cincinnati Flying Pig Marathon emphasizing the proportion of locals to nonlocals. They found that the local economic impact accounted for $25 \%$ of the total economic impact that it should be taken into account because if there was no local marathon event, a portion of the locals would have run (and spend money) in marathons outside their locality.

Soderberg (2014) examined an important aspect of marathons, namely the pricing (participation fee). This is important because some marathon races have attracted many participants and continued to grow making it difficult to accommodate demand. Increasing prices is that only long term solution. Increasing the participation fee may not be the best solution but as Soderberg argues the organizers can give new attributes to the event and price them.

No matter how the experience of the participants is affected, a memorable experience will bring more people in the future but at the same time it will also affect the exports of local products and bring an inflow of investments from outside the area either national or international. And this is the neglected impact of all the economic studies of sport tourism events including the marathon events. It is really surprising that there is a dearth of such studies because one of the reasons for hosting such events is to show the world that the city or the country is open to the world. It is a showcase of what a given region has to offer to the world in terms of economy, society, culture etc. If these impacts are positive, then it makes perfect economic sense why local authorities host such events. After all, if the economic benefits do not cover the economic costs, why do local authorities continue with the organization of such events? Non economic reasons have been proposed, but to an economist they do not sound very persuasive. Local pride is one of the arguments, but is the organization of a marathon event the best way to maximize local pride? What about other events which are much larger and require the commitment of huge financial resources such as the Olympics or the Football World Cup? Why do 
local authorities or countries devote huge amounts of public funding to organize such events?

Rose and Spiegel (2011) provided an answer to these questions. Analyzing the impact of the Olympics they concluded that such mega events have major economic impacts which are not captured by the economic impact studies. According to the authors, a city/country which decides to bid and host for such mega events sends a positive signal to the world that they are open for business. The successful organization of such events enhances the power of this signal. The authors find not only that hosting an event has a positive impact but also that unsuccessfully bidding for the Olympics has a positive impact. However, these results have been challenged by Maennig and Richter (2012). They claimed that if the selection bias is taken into consideration the Olympic effect disappears.

The positive economic impact comes from three interrelated sources. First, the positive effect of hosting a marathon event will stimulate future tourist visits, not only during the event. After all, one of the most important economic effects of the Olympic Games is the post-Olympic effect on international tourist arrivals. Second, the publicity of the event will increase the interest and therefore the demand for local products when they do not visit the area. This will increase the exports. The third and maybe the most important effect, hosting such events shows to the world that not only international tourists are welcome but foreign capital investments are welcome as well. International capital flows can be the most important long run impact of a marathon event.

The above positive economic effects will not come automatically by organizing a marathon sport tourism event. No matter how successful the organization of the event is, the additional benefits can only accrue as the result of a systematic effort to attract capital and promote exports. A successful marathon event is only the beginning, as is the case with a marathon race itself. The promotion of exports and the inflow of capital is by itself a marathon competition at the world level. Some thoughts on these issues are examined in the next section of this paper.

\section{The Athens Marathon}

This section is developed with special references to Athens (Greece) and the marathon it organizes every year. The Athens's case is of great interest because in 2004 it organized the Olympic Games while in the 1980s made an unsuccessful bid for the 1996 Olympic Games. Since 1972 an annual marathon event which is called authentic, because it starts from the Village of Marathon and ends at the Panathinaikon Stadium where the first modern Olympic Games were held in 1896, is organized. The question is what is in for the city of Athens and Greece. Apart from the direct effect of participants and other visitors, what are the long term impacts on international tourism, exports and investment, if any? It seems that these effects have not been the focus of the 
attention of policy makers at all levels of government or other stakeholders such as the Hotel and Business Associations.

Papanikos (1999) has examined in an ex ante study the Olympic Games of 2004 on international Greek tourism arrivals and generally on Greek economy. It was estimated that annual effect on GDP would be $0.8 \%$ creating 32,000 new jobs per year. It was estimated that an additional 6 million of international arrivals will come to Greece during the 1998-2011 period because of the Games. Even though international tourism arrivals have increased from about 14 millions in 2005 (the first year after the games of 2004) to more than 24 millions in 2014, this important impact was not as strong the first five years after the games primarily because the real effective exchange euro was heavily overvalued during this period (Papanikos 2015).

No evidence exist on exports and foreign direct investment as the result of the Olympic Games. Unfortunately, after 2004, even the Olympic venues, especially in the area of the former airport (Ellinikon), did not attract any foreign or domestic investments because of delays due to red tape and political incompetence (Kasimati 2015). This may explain why studies like the one by Kasimati and Dawson (2009) find that the long run economic effect is modest. This low economic effect might have the result of the wider macroeconomic and microeconomic Greek environment and not so much the Olympic effect. Exports and foreign direct investment requires a friendly political, economic, social and technological environment and this was lacking in the post 2004 period in Greece. I have examined in detail this unfavorable environment in my book (Papanikos 2014).

As far as the annual marathon event, the authentic as it is called, no study exist which assess the economic impact ${ }^{1}$. There are two policies related to Marathon. One is the organization and managing of the Marathon event which requires the involvement of many government and non-government stakeholders such as the local authorities which will provide the amenities and the permission to use public spaces for the event, the organizing committee which is usually a non-government and non-profit entity and of course private enterprises which sponsor the event following their own business policy strategies. All these interested parties are directly related and have competence only for the marathon event itself. There is no entity which can take advantage of the effects such events have in promoting the exports of a region/country and/or attracting foreign direct investment. Unless this is taken care of, important events such as the Athens annual marathon will have small if any economic effects.

\footnotetext{
${ }^{1}$ It is of interest to note that Kurtzman (2005) devotes a special section on the development of sports tourism in Greece. In his assessment of the Greek potential he states on p. 50 "Membership in the European Economic Community has activated a dynamic economic climate within Greece. For tourism, opportunities exist to redeem limited investment costs for the development of destinations. Potential growth within the tourism industry due to the Athens Games, has been recognized by the Government of Greece as a valuable addition to their economic base-and Sports Tourism has received a comparable priority status. Potentials also exist within the country derived from the resorts, attractions and tour categories of sports tourism". Alas, the events after the Olympic Games did not vindicate such statements.
} 


\section{Conclusions}

Marathons are important events. They can have positive economic effects if they are organized efficiently and effectively. The Athens marathon is a very good example of an event with a real brand name which has no long term positive economic effects. This is not and could not be the responsibility of all those who are responsible with the organization of the management and the marketing of the marathon event itself. It is not their responsibility. Other entities such as business associations and even individual entrepreneurs can find it profitable to exploit the potential of the Athens marathon. However, it is the responsibility of all the stakeholders who are directly involved in the organization of the Athens marathon to provide ex ante and ex post honest economic evaluations of the event. Such information will be very useful to all who have an interest in capitalizing on the publicity of the Athens marathon.

The conclusion which emerges from the literature of the economic effects of marathons as sport tourism effects is that these depend very much on actions which can be taken by the interested stakeholders to capitalize on the positive publicity of the event. Consequently, further research is required to find out (a) what are the economic benefits and costs of the Athens marathon and (b) what are the synergies that can result form the Athens marathon which can promote exports and investments in the city. With this in mind, it might require a reengineering of the entire organization of the Athens marathon by bringing in different stakeholders and even individuals.

\section{References}

Baade R, Matheson V (2004) The quest for the cup: assessing the economic impact of the world cup. Regional Studies 38(4): 343-54.

Baade RA, Dye RF (1988) Sports stadiums and area development: A critical review. Economic Development Quarterly 2(3): 265-275.

Baumann RW, Matheson VA, Muroi C (2009) Bowling in hawaii examining the effectiveness of sports-based tourism strategies. Journal of Sports Economics 10(1): 107-123.

Beritelli P, Boksberger PE, Weinert R (2004) An integrated concept of financing hallmark sport events. Tourism Review 59(2): 33-37.

Burgan B, Mules T (1992) Economic impact of sporting events. Annals of Tourism Research 19(4): 700-710.

Brewer RM, Freeman KM (2015) Inexpensively estimating the economic impact of sports tourism programs in small American cities. Indiana Business Review Spring: $1-6$.

Carson RT (2012) Contingent valuation: a practical alternative when prices aren't available. Journal of Economic Perspectives 26(4): 27-42.

Coates D (2007) Stadiums and arenas: economic development or economic redistribution?. Contemporary Economic Policy 25(4): 565-577.

Cobb S, Olberding DJ (2007) The importance of import substitution in marathon economic impact analysis. International Journal of Sport Finance 2: 108-118.

Crompton J (2006) Economic impact studies: Instruments for political shenanigans?. Journal of Travel Research 45(1): 67-82. 
Crompton J (1999) The economic impact of sports tournaments and events. Parks \& Recreation 34(9): 142-151.

Crompton J, Lee S (2000) The economic impact of 30 sports tournaments, festivals, and spectator events in seven US cities. Journal of Park and Recreation Administration 18(2): 107-126.

Davakos H (2007) Economic impact of $10 \mathrm{~K}$ race on the Greater Charleston, SC area. IASE/NAASE Working Paper Series, Paper No. 07-18.

De Nooij M (2014) Economic Impact Analysis versus Cost Benefit Analysis for a Medium Sized Sport Event - A Further Improvement. Mimeo.

Dwyer L, Forsyth P, Spurr R (2004) Evaluating tourism's economic effects: new and old approaches. Tourism Management 25(3): 307-317.

Filo K, Chen N, King C, Funk DC (2013) Sport tourists' involvement with a destination: a stage-based examination. Journal of Hospitality \& Tourism Research 37(1): 100-124.

Frechtling DC (2006) An assessment of visitor expenditure methods and models. Journal of Travel Research 45(1): 26-35.

Getz D (2008) Event tourism: definition, evolution, and research. Tourism Management 29(3): 403-428.

Gratton C, Shibli S, Coleman R (2006) The economic impact of major sports events: a review of ten events in the UK. Sociological Review 54(s2): 41-58.

Gratton C, Shibli S, Coleman R (2005) Sport and economic regeneration in cities. Urban Studies 42(5/6): 985-999.

Green BC (2001) Leveraging subculture and identity to promote sport events. Sport Management Review 4(1): 1-19.

Hausman J (2012) Contingent valuation: from dubious to hopeless. Journal of Economic Perspectives 26(4): 43-56.

Huang H, Mao LL, Kim SK, Zhang JJ (2014) Assessing the economic impact of three major sport events in China: the perspective of attendees. Tourism Economics 20(6): 1277-1296.

Jasmand S, Maennig W (2008) Regional income and employment effects of the 1972 Munich Olympic Summer Games. Regional Studies. 42(7): 991-1002.

Kasimati E (2015) Post Olympic use of the Olympic venues: the case of Greece. Athens Journal of Sports 2(3): 167-184.

Kasimati E, Dawson P (2009) Assessing the impact of the 2004 Olympic Games on the Greek economy: a small macro-econometric model. Economic Modelling 26(1): 139-146.

King C, Chen N, Funk DC (2015) Exploring destination image decay: a study of sport tourists' destination image change after event participation. Journal of Hospitality \& Tourism Research 39(1): 3-31.

Kruger M, Saayman M (2012) Creating a memorable spectator experience at the two Oceans Marathon. Journal of Sport \& Tourism 17 (1): 63-77.

Kurtzman J (2005) Economic impact: sport tourism and the city. Journal of Sport \& Tourism 10(1): 47-71.

Lamla MJ, Straub M, Girsberger EM (2014) On the economic impact of international sport events: micro-evidence from survey data at the EURO 2008. Applied Economics 46(15): 1693-1703.

Li SN, Blake A, Thomas R (2013) Modelling the economic impact of sports events: the case of the Beijing Olympics. Economic Modelling 30(January): 235-244.

Matheson V (2009) Economic multipliers and mega-event analysis. International Journal of Sport Finance 4(1): 63-70. 
Maennig M, Richter F (2012) Exports and Olympic games: is there a signal effect?. Journal of Sports Economics 13(6): 635-641.

Owen JG (2005) Estimating the cost and benefit of hosting Olympic games. The Industrial Geographer 1(3): 1-18.

Papanikos GT (2015) The real exchange rate of euro and Greek economic growth. Journal of Economic Asymmetries 12 (November): 100-109.

Papanikos GT (2014) The Greek Economic Crisis: A Class Analysis in Support of Austerity Measures. Athens: Athens Institute for Education and Research. (in Greek) http://www.atiner.gr/gtp/2014papbook.pdf

Papanikos GT (2005) The Greek tourism revenues. Athens, Greece: Research Institute for Tourism. (in Greek).

Papanikos GT (2003) Development effects of the 2004 Olympic games: post Olympic exploitation of infrastructures and equipment. Report Prepared for the Government of Greece. http://www.atiner.gr/gtp/GGOA_Periexomena.pdf.

Papanikos GT (1999) The Olympic games of 2004 and its effects on Greek tourism. Athens, Greece: Research Institute for Tourism. (in Greek).

Porter P, Fletcher D (2008) The economic impact of the Olympic games: ex ante predictions and ex post reality. Journal of Sport Management 22(4): 470-486.

Rose AK, Spiegel MM (2011) The Olympic effect. The Economic Journal 121(June): 652-677.

Soderberg M (2014) Willingness to pay for nontraditional attributes among participants of a long-distance running race. Journal of Sports Economics 15(3): 285-302.

Spilling OR (1996) Mega event as strategy for regional development the case of the 1994 Lillehammer Winter Olympics. Entrepreneurship \& Regional Development: An International Journal 8(4): 321-343.

Szymanski S (2002) The economic impact of the World Cup. World Economics 3(1): 169-177.

Taks M, Kesenne S, Chalip L, Green CB (2011) Economic impact analysis versus cost benefit analysis: the case of a medium-sized sport event. International Journal of Sport Finance 6(3): 187-203.

Wicker P, Hallmann K, Zhang JJ (2012) What is influencing consumer expenditure and intention to revisit? an investigation of marathon events. Journal of Sport \& Tourism 17(3): 165-182. 
